\title{
The Application of Quantum Energy Saver on Engine
}

\author{
Xiong Fang ${ }^{1, a}$, Wenwu $\mathrm{Mao}^{2}$, Xisheng Shen ${ }^{1}$ and Zhixin Chen ${ }^{1}$ \\ ${ }^{1}$ Fishery Machinery and Instrument Research Institute, Chinese Academy of Fishery Sciences Research Laborato- \\ ry of marine fishing vessels and equipment, Shanghai, China \\ ${ }^{2}$ School of Engineering, Shanghai Ocean University, Shanghai, China
}

\begin{abstract}
In order to reduce diesel fuel consumption, this paper conducts the research in view of a new type of quantum energy saving device, and then produce the sample and applied on automobile engine, Detect fuel use of an automobile by automobile fuel saving technology assessment methods from the department of transportation. Compare the changes of fuel use before and after installation of quantum energy saving device on the same car, and give the feedback of energy saving capability. The result shows, after installed quantum energy saver, both fuel consumption and the smoke of tail gas has decreased. The analysis and application of this paper carry out the conclusion that the quantum energy saver can play an important role in energy saving and emission reduction, and provide a reference for other related research.
\end{abstract}

The automobile has become one of the most important means of transportation in the world and it's the symbol of development of science and technology. All developed countries take the automobile industry as the mainstay industry of the national economy. Automobile industry related to national economy and has played a huge role in promoting the social economic development and scientific and technological development. At the same time the automobile is also a sign of the development level of social life. In 2015 Both China's auto production and sales reached 24.5 million. The market share has reached from $3.5 \%$ in 2000 to $28 \%$ and become an important part of the world's automotive industry [1].

Engine is the only source of vehicle power. An engine with reliable quality and low energy consumption will provide huge power to the auto industry of China and make it develop quickly, continuously and healthy.

For ordinary consumers, the cost of fuel accounted for $40 \%-50 \%$ of the whole cost, even more. With the decrease of oil production and the increase of fuel price, consumers' travel costs are higher and higher. In order to save fuel and reduce exhaust emissions, most of automobile and engine manufacturers have adopted many measures such as use small displacement engine with turbocharger technology, or adjust throttle to make the fuel burned more fully. But the methods described above have some defects, the turbocharger technology is unstable and maintenance cost is high, also the stability of throttle adjustment remains to be improved [2]. In this paper, by the research and experiment of a new type of quantum energy saver, achieve the purpose of energy saving and consumption reduction.

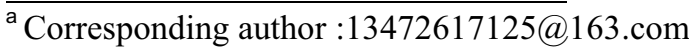




\section{Quantum Energy}

In 1990, the German physicist Max Planck found in the research of electromagnetic radiation energy distribution: The emission and absorption of electromagnetic waves are not continuous, but one by one. Every one has energy; the energy could be a multiple of an elementary unit:

$$
\varepsilon_{0}=h v
$$

where $\varepsilon_{0}$ is energy, h is Planck's constant, and $v$ is the frequency of the radiation. He called the energy unit which is the minimum and cannot be divided as energy quantum. When explain the distribution of the energy of the electromagnetic radiation, Planck first creatively put forward the concept of "quantum" and introduce the Planck's constant; There are more than 100 years when "quantum" was firstly introduced. Further research shows, in the micro field, some physical quantities are also jumping in the smallest units, not continuous, and the smallest units are called the quantum of the physical quantity. Such as: energy quantum, light quantum, flux quantum, sound quantum and etc [3].

In the composition of the universe, there are different levels of the smallest units, such as: all kinds of molecules, atoms, neutrons, protons, electrons, etc. In the range of $10^{-10} \mathrm{~m}$ and smaller scale, the material movement has obviously shown "quantized" characteristics. And in which, the Planck constant always plays an important role.

At the end of the nineteenth Century, scientists attempted to understand the micro world classical mechanics and macro view, but they failed, which reflected the contradiction between people's subjective understanding and objective reality. In order to solve this contradiction, the only way is to change the view of microscopic particles and get knowledge from practice. From the classical physics, we know that all microscopic particles have the property of the particle and the property of the wave. In 1905, the German physicist Albert Einstein's, 1879 - 1955) introduced the concept of quantum and photons and also put forward the "wave-particle duality" of the light. The concept of particle are mutually exclusive, but in a unified entity and it is shown by De Broglie equation

$$
\lambda=h / p
$$

The De Broglie wavelength is the wavelength, $\lambda$, associated with a massive particle and is related to its momentum, $\mathrm{p}$, through the Planck constant, $\mathrm{h}[4]$.

Entire quantum mechanics is based on the concept of wave-particle duality and uncertainty relationship is very important. [5] When it is out of the accuracy which is ruled by uncertainty relationship, we can follow the classical laws, otherwise, follow the quantum laws. Therefore, the uncertainty relation is the boundary of quantum mechanics and classical mechanics; it reflects the process from quantitative change to qualitative change.

\section{Quantum technologies}

Quantum theory has been perfected and developed from theoretical research to practical application. This kind of wave can be stored in different carrier by the laser sintering machine, which makes it produce energy value in different applications. Materials which have been conversed by quantum energy create billion/sec supermicro wave in the effect of light, force and heat. When the liquid flows through the quantum pipe, hydrocarbon chains are rearranged into a long molecular chain, which greatly improves the combustion and explosion, so it can reduce the fuel consumption.

\section{Designs and application}

\subsection{Structure design of quantum energy saver}


The new quantum energy saver is a cylinder which is composed of two symmetrical quantum tile pipes. There are two grooves on both sides of the cylinder and there is fastener in the middle. All grooves and fasten are used to fix the cylinder on the pipe, so fluid can flow through the pipe and affected by the cylinder. The tile tubes are used to enhance the physical and chemical properties of the fluid in the pipe and reach the goal of high efficiency and optimization. Structure is shown in Figure 1.

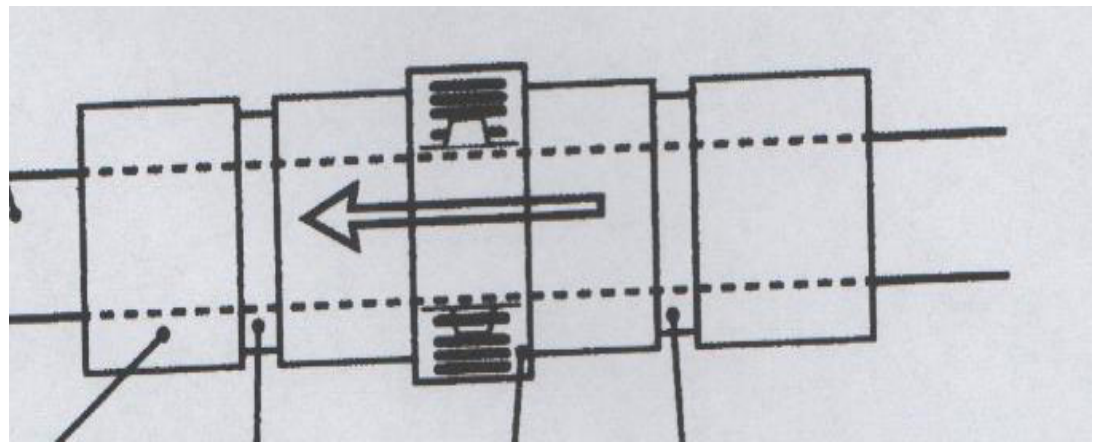

Figure 1. Structure of quantum energy saver

\subsection{Application of engine}

\subsubsection{Application background and objects}

In the new century, China's national standard of living has improved rapidly and automotive industry is developing quickly. As an important part of automobile industry, automobile components industry has been widely concerned. During 2000-2012, the engine industry in the proportion of GDP has increased a lot and especially in 2014. According to statistics, in 2014 the total number of engine production in China was 21.0816 million, increased 5.78\%, total engine sales number was 21.1695 million, increased $9.64 \%$. China has become a big country of automobile engine production and each year the number of automobile engine production accounts for about $1 / 4$ of the world's total engine production [6]. So the energy saving and emission reduction of engine is a hot topic in current years. Major domestic and foreign automobile manufacturers, relevant research institutions have focused on this hope to be able to make a breakthrough. So we put the engine as the test object to verify fuel saving and emission reduction effect of quantum energy saver.

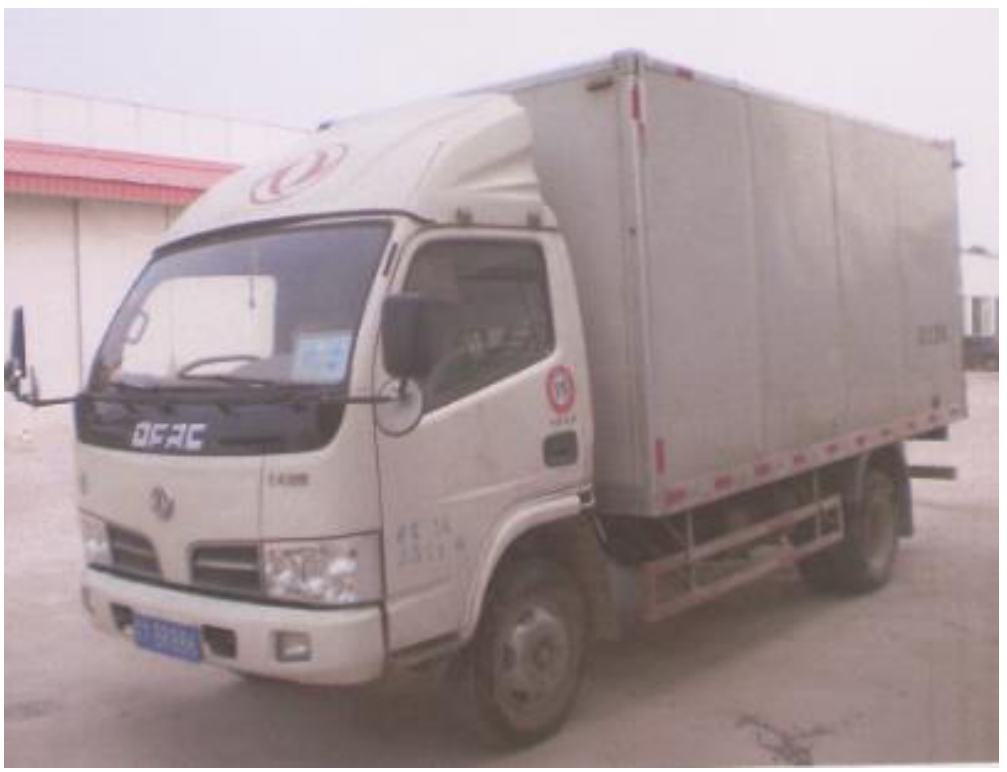

Figure 2. Dongfeng EQ5041XXY35D3AC automobile 


\subsubsection{Authentication}

The object of this experiment is the Dongfeng EQ5041XXY35D3AC automobile, as shown in figure 2. The basis for the test was issued by the Ministry of transport GB/T14951-2007 《Automobile fuel saving technology assessment method $》$. The test site is in the Ministry of transport road traffic test site, engine laboratory. The main instruments of the test are non-contact speed analyzer, fuel flow meter, extinction type smoke meter, engine speed and so on. Test method was to put the quantum energy saver on the automobile engine oil inlet pipe, the location was near the end of the engine and then fasten belt and fixed the saver. Finally, drive the vehicle in constant speed and finish the fuel consumption test and free acceleration smoke (light reflection method) test, as shown in Figure 3.

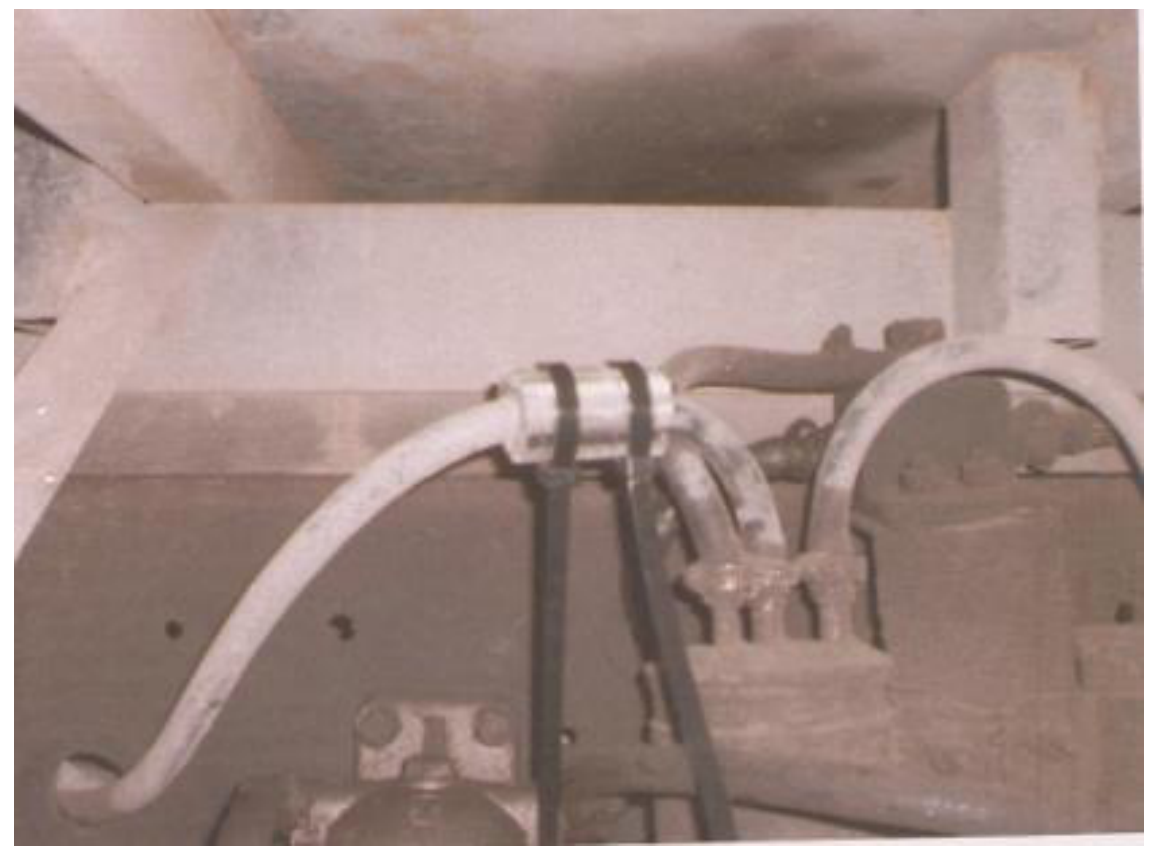

Figure 3. Installation of quantum energy saver

\subsection{Results}

Before installing energy saver, tested fuel consumption in $30 \mathrm{~km} / \mathrm{h}, 45 \mathrm{~km} / \mathrm{h}, 60 \mathrm{~km} / \mathrm{h}, 75 \mathrm{~km} / \mathrm{h}$ and 90 $\mathrm{km} / \mathrm{h}$ and then, compare with the data when saver was installed in all five speeds. The oil savings were $0.07 \mathrm{~L}, 0.11 \mathrm{~L}, 0.21 \mathrm{~L}, 0.17 \mathrm{~L}, 0.3 \mathrm{~L}$ and the rates were $1.5 \%, 1.6 \%, 3 \%, 2 \%, 2.9 \%$, integrated saving rate was $2.2 \%$. The free acceleration smoke (light reflection method) purification rate was $4.3 \%$. Results are shown in Table 1 and 2.

Table 1: Test data

\begin{tabular}{|c|c|c|c|c|c|}
\hline Nominal speed $(\mathrm{KM} / \mathrm{h})$ & 30 & 45 & 60 & 75 & 90 \\
\hline Actual Fuel consumption /speed data 0 & $4.91 / 29.8$ & $6.06 / 45.0$ & $7.34 / 59.9$ & $8.74 / 75.0$ & $11.0 / 89.8$ \\
\hline
\end{tabular}




\begin{tabular}{|c|c|c|c|c|c|}
\hline Actual Fuel consumption /speed data 1 & $4.85 / 30.0$ & $5.95 / 44.9$ & $7.13 / 60.1$ & $8.55 / 74.9$ & $10.7 / 90.0$ \\
\hline $\begin{array}{c}\text { Calculation of fuel saving based on data } \\
0 \text { and data 1 }\end{array}$ & 0.07 & 0.11 & 0.21 & 0.17 & 0.3 \\
\hline $\begin{array}{c}\text { Calculation of saving rate based on data } \\
0 \text { and data 1 }\end{array}$ & $1.5 \%$ & $1.6 \%$ & $3 \%$ & $2 \%$ & $2.9 \%$ \\
\hline
\end{tabular}

Note: Data 0 is the vehicle without quantum energy saver, data 1 is with the saver Units of fuel consumption and fuel saving: $\mathrm{Kg} / \mathrm{Km}$

Table 2: Test data

\begin{tabular}{|c|c|}
\hline & Free acceleration smoke (light reflection method $)\left(\mathrm{m}^{-1}\right)$ \\
\hline Vehicle without quantum energy saver & 1.61 \\
\hline Vehicle with quantum energy saver & 1.54 \\
\hline Purification rate (\%) & 4.3 \\
\hline
\end{tabular}

In the test of the automobile engine, quantum energy saver has obvious effect of fuel saving, There are no adverse effects and accidents during the test, the engine operated in good condition and energy saver was used in steady state.

\section{Conclusions}

According to the experiment above, use of new quantum energy saver can obviously save fuel and reduce tail gas emission. Data shows it saved most fuel when driven in $90 \mathrm{KM} / \mathrm{H}$ and when driven in $60 \mathrm{KM} / \mathrm{H}$ the fuel saving ratio is highest. The conclusion can be drawn that the quantum energy saver is particularly suitable for city roads and highways and the smoke emission rate of the exhaust gas is also improved.

Focus on the development direction of energy-saving and emission-reduction; design the new quantum energy saver by the research of quantum theory. There are many advantages such as simple structure, convenient to install and there is no adverse reaction.

If the new quantum energy saver can be promoted to the automotive industry and all automobiles install energy savers, it can save nearly 100 thousand tons of oil and billions of cost. Also provide support and protection for the country's sustainable development and green ecological environment.

\section{References}

1. L. J. Guan, Modern Industrial Economy and Informationization, 6, 10-11 (2016)

2. J. Li, Z. L. Hei, Science \& Technology Vision, No.12, 93-94 (2015)

3. R. X. Rui, H. T. Chen, International Electronic Elements, 21, 15-16 (2013)

4. J. H. Gong, J. F. Gao, L. H. Duo, Journal of Teaching and Management, No.12, 99-100 (2006)

5. J. K. Fen, Discovery of Nature, 4, No.1, 135-136 (1985)

6. Y. Wang, Dynamics of Industrial Economy in China, No.9, 41-43 (2014) 